\title{
Perforator flaps based on the deltoid branch of the thoracoacromial artery: anatomical study
}

\author{
Philippe Manyacka Ma Nyemb $^{1,2}$ (D), Christian Fontaine ${ }^{3}$ (D), Véronique Duquennoy-Martinot ${ }^{4}$ (D), \\ Xavier Demondion ${ }^{3,5}$ iD \\ ${ }^{1}$ Department of Anatomy and Organogenesis, School of Medicine, Gaston Berger University, Saint-Louis, Senegal \\ ${ }^{2}$ Department of General Surgery, Regional Hospital, Saint-Louis, Senegal \\ ${ }^{3}$ Department of Anatomy and Organogenesis, Henri Warembourg Faculty of Medicine, Université de Lille 2, Lille, France \\ ${ }^{4}$ Department of Plastic, Esthetic and Reconstructive Surgery, Roger Salengro Hospital, Lille University Hospital, Lille, France \\ 'Department of Musculoskelettal Imaging, Roger Salengro Hospital, Lille University Hospital, Lille, France
}

\begin{abstract}
Objectives: Tissue defects in the lateral triangle of the neck and the anterior cervical region represent a high demand for plastic and reconstructive surgery. Their management most often requires regional or free flaps. The perforator flap based on the deltoid branch of the thoracoacromial artery (TAA) may be a good solution for these indications. The objective of this work is to propose anatomical landmarks to raise perforator flaps pedicled on the deltoid branch of the TAA.

Methods: We carried out dissection of 24 perforator flaps based on the deltoid branch of the TAA, in body donor specimens preserved in a glycerin-rich, formalin-free solution. The TAA was first injected with methylene blue. The vascular territory, location of perforators relative to known landmarks, along with the flap's potential amplitude and arc of rotation were studied.

Results: The main perforating arteries of the flap were located in the middle of the deltopectoral groove, often surrounded by adipose tissue in 18 out of 24 dissections. In 22 out of 24 dissections, there were at least 2 perforator arteries originating from the deltoid branch. The average diameter of the perforator arteries was $1 \mathrm{~mm}$. The flap's amplitude of movement made it possible to reach in all cases the lateral triangle of the neck and the anterolateral cervical region.

Conclusion: The thoracoacromial artery has already been used for perforator flaps. However, the individualization of its deltoid branch offers to practitioners new surgical options. This anatomical study of the perforator flap based on the deltoid branch of the TAA made it possible to review the anatomical bases for the raising of this flap, and to fix useful landmarks for the surgeon in order to propose an easily feasible surgical technique.
\end{abstract}

Keywords: deltoid branch; perforator flap; thoracoacromial artery; vascular territory

Anatomy 2021;15(1):36-43 C2021 Turkish Society of Anatomy and Clinical Anatomy (TSACA)

\section{Introduction}

For many years, covering the tissue defects of the lateral triangle of the neck and the anterior cervical region has required complex techniques because these two regions are limited by the course of the sternocleidomastoid muscle. ${ }^{[1,2]}$ The deltoid region has never been exploited to fill in for these tissue defects. Indeed, in the deltoid region, muscular and musculocutaneous flaps are mostly used in other indications. ${ }^{[3]}$ In this case the morbidity on the deltoid muscle is high, even when the donor site can be primarily closed. ${ }^{[3]}$ More recently, the advent of perforator flaps marked a turning point in the reconstruction of tissue defects of the neck. Besides, in the indications of loss of substances from the lateral triangle of the neck and the anterior cervical region, the perforator flap of the cervical transverse artery can provide an efficient solution. ${ }^{[4]}$ The perforator flaps are based on the muscu-

This study was a poster presentation at the 102nd Congress of the French Association of Morphologists, 11th-12th March 2021, Montpellier, France. 
locutaneous perforators which cross the muscle and end on a skin pallet without participating in the muscular vascularization. ${ }^{[5]}$ They therefore better match for filling (or repairing) the loss of substance in question, with reduced morbidity and a wider choice of donor sites.

The thoracoacromial artery (TAA) originates below the lateral half of the clavicle. It is a big artery located on the anterior face of the axillary artery; its initial portion is located behind the cranial margin of the pectoralis minor muscle. ${ }^{[6-9]}$ The deltoid and pectoral branches are the two permanent voluminous arteries arising from the TAA. It is also found inconstantly two other variable branches: a clavicular branch (arising from the TAA) and an acromial branch arising from the deltoid branch (when present). ${ }^{[6-9]}$ These four arteries (and their satellite veins) come out of the TAA just below the clavicle. They meet on their way the pectoralis major muscle which they cross from inside out below the clavicle. ${ }^{[0-9]}$ The clavicular branch medially supplies the pectoralis major muscle, which is laterally irrigated by the deltoid and acromial branches. ${ }^{[6-9]}$ The deltoid and acromial branches provide musculocutaneous perforators for the subcutaneous tissue and skin of the upper portion of the pectoral wall. It is common for the acromial branch to arise directly from the deltoid branch; this acromial branch also provides a musculoskeletal perforator for the subcutaneous tissue and skin above the deltoid muscle and the clavicle (acromial end). ${ }^{[6-9]}$ The deltoid branch crosses the upper part of the deltopectoral groove and ramifies into a superficial and a deep branch. ${ }^{[10,11]}$ The duplication of the fascia houses a small canal in which the deep branch travels inside the deltopectoral groove. This deep branch crosses superficial planes of its fascial canal, at the level of the intermuscular space. It reaches the subcutaneous tissue and irrigates the skin overlying both the pectoralis major tendon and the insertional portion of the deltoid. ${ }^{[10,11]}$

In the literature, the perforator flap based on the deltoid branch of the TAA has not yet been the subject of anatomical study, this work therefore represents a pioneer study in this area. The aim of this study was to highlight the feasibility of a perforator flap based on the deltoid branch of the TAA, in covering tissue defects within cervical regions.

\section{Materials and Methods}

Prior to our work, all the institutional procedures concerning cadaveric dissection were respected, as well as the ethical framework. From an ethical point of view, our work was based on the legislation at the time of the study. We dissected 24 anatomical regions belonging to 12 cadavers (12 right and 12 left upper limbs). The 12 non- formalin fixed cadavers consisted of 9 males and 3 females. The mean age was 69 years (range 47-88). No history of surgery or deformity was reported on the cadavers. The areas targeted for dissection were supraclavicular, pectoral and deltoid regions. For embalming we used a glycerinrich, formalin-free solution. Such a solution is used in the laboratory of anatomy of Lille to preserve tissue suppleness.

Our dissections were carried out in several phases. For the first phase, the cadaver was placed in a supine position, the lateral triangle of the neck was dissected and the clavicle removed. We dissected, identified and marked the subclavian artery and its branches. The origin of the TAA was exposed on the anterior side of the first segment of the axillary artery. A mixture (gelatin, methylene blue and iron powder) was used for infecting the TAA (Figures 1a and b). The cadaver was then refrozen for 24 hours for hardening the injected mixture.

In the second phase, the cadaver was thawed out at room temperature and then placed in dorsal decubitus to dissect the subcutaneous tissue and skin. For this phase, the dissection made it possible to completely circumscribe the cutaneous perforasome, and to detach it while sparing the muscular layer. The superficial plane was then dissected and separated from the muscle layer over the entire surface of the perforasome. Special care was taken at this phase of the dissection to prevent damaging veins accompanying each perforating artery (Figures 2, 3a and b). During this procedure, the perforating arteries were dissected, inventoried and listed according to their characteristics (location, dimensions, orientation, frequency and size of the cutaneous perforasome). Perforasome area was calculated based on a circular shape (radius $\times$ radius $\times \pi$ ) or elliptical shape (long radius $\times$ small radius $\times \pi$ ). Dissection of perforators was then continued through the muscle while preserving the integrity of the pectoralis major muscle. The superficial layer of the perforator flap was then completely harvested with its pedicle. All measurements were made by the same operator. The following equipment was used for the various measurements: felt pen, metal rulers graduated in millimeters, surgical suture, calliper, thumbtacks, and magnifying glasses.

\section{Results}

The TAA had an average diameter of $2 \mathrm{~mm}$. An average of 2.4 perforators (range: $1-3$ ) were found on the perforasome corresponding to the territory of the TAA's deltoid branch. The average diameter of these perforators was 0.9 (range: $0.5-1.5) \mathrm{mm}$. The perforators of the deltoid branch are mainly observed over an area of $4 \mathrm{~cm}^{2}$ project- 

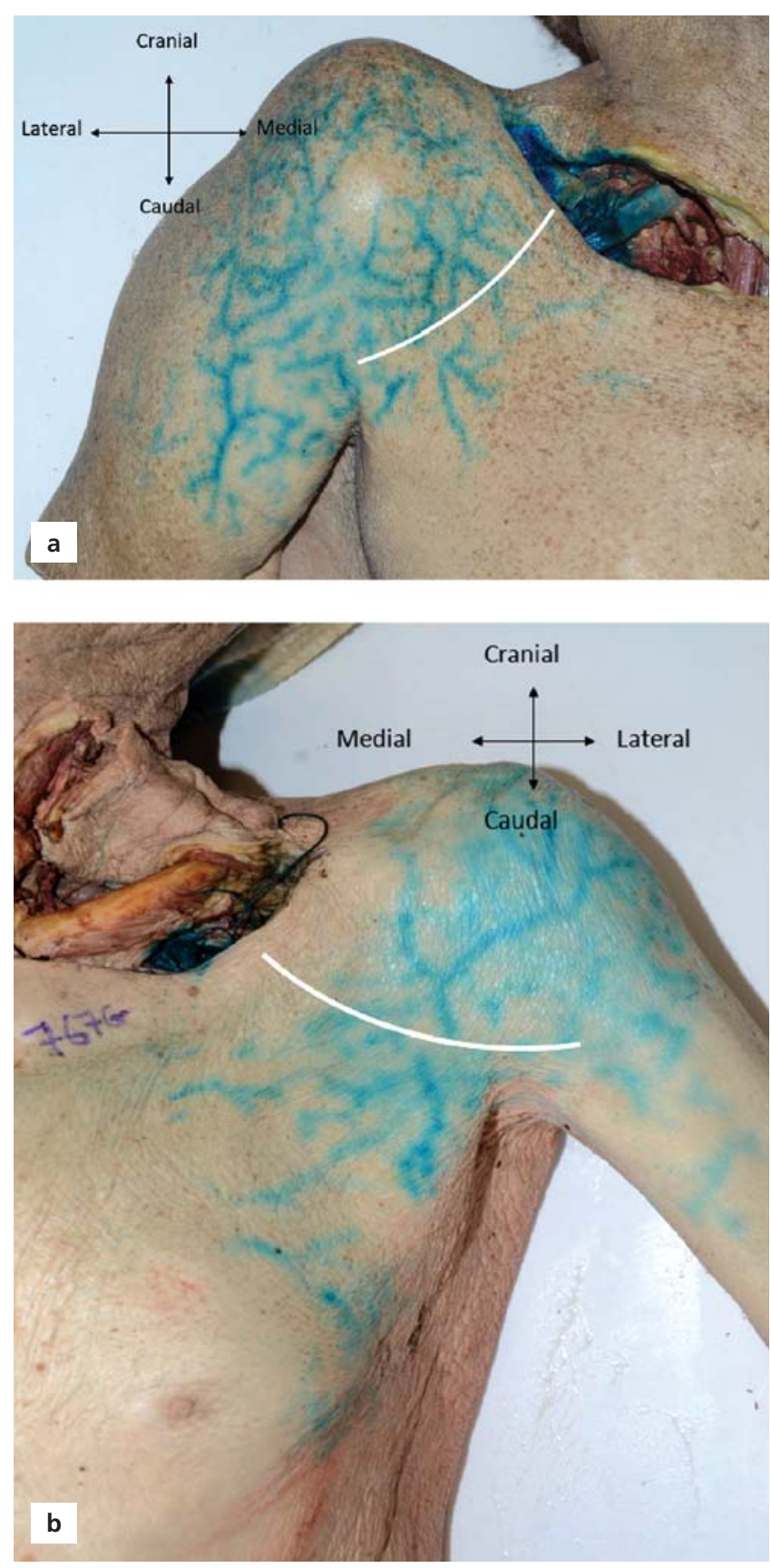

Figure 1. Injection of dye on the right (a) and left (b) sides into the deltoid and pectoral branches of the of the thoracoacromial artery in two subjects. The deltopectoral groove is represented as a white line (specimen numbers 17 and 2).

ing near the middle third of the deltopectoral groove (Figure 4). The average dimensions of the perforasome were $6 \times 7 \mathrm{~cm}$, corresponding to a mean area of 33 (range: $23.5-50) \mathrm{cm}^{2}$. Its general orientation was descending on the ventral side of the deltoid muscle and slightly oblique infero-laterally (Figure 5). The extramuscular pedicle had

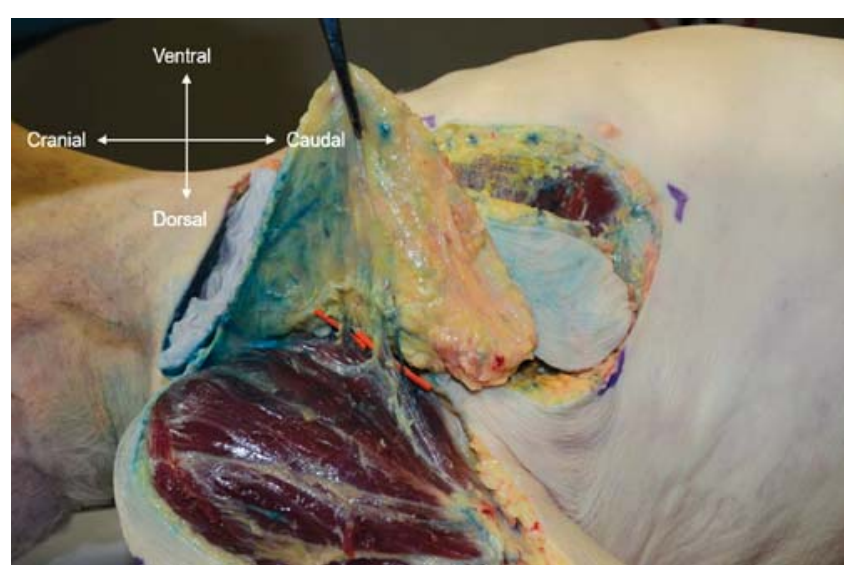

Figure 2. Dissecting the vascular territory of the deltoid branch of the thoraco-acromial artery (specimen number 13).

an average length of 1.8 (range: $10-30) \mathrm{cm}$ and the transmuscular pedicle had an average length of 7 (range: 5-10) $\mathrm{cm}$. A $180^{\circ}$ arc of rotation was possible from the pivot point (Figure 6). In 19 of the 24 specimens, the deltoid branch of the TAA and its perforators converged over the middle third of the deltopectoral groove (pivot point). It also appears that the acromial branch is always a daughter branch from the deltoid branch.

The following topographic boundaries can be used when dissecting this flap, although the perforasome area often extends beyond these boundaries: caudally the horizontal line passing through the nipple and the 4th intercostal space, laterally the vertical line passing through the insertion of the deltoid muscle, medially the anterior edge of the deltoid, the apex of the perforating flap lying near its pedicle, along the deltopectoral groove. The more detailed results are presented in Table $\mathbf{1}$ and Figures 1-3.

\section{Discussion}

Several anatomical and surgical series have already proposed the musculocutaneous flaps of the thoracic muscles in the indications of tissue defects in the lateral triangle of the neck and the anterior cervical region. ${ }^{[12]}$ More recently the fasciocutaneous and perforator flaps of pectoral region have been studied in the same indications. ${ }^{[1,2]}$ In the loss of substance of the supraclavicular area, the needs for soft tissue often require the harvesting of local, regional or distant flaps. In these indications, it is often the musculocutaneous flaps such as the flap of the pectoralis major muscle or the flap of the trapezius muscle which are preferred to conventionnal propeller perforator flaps. Traditionally, the musculocutaneous flap of the pectoralis major and the deltopectoral flap 

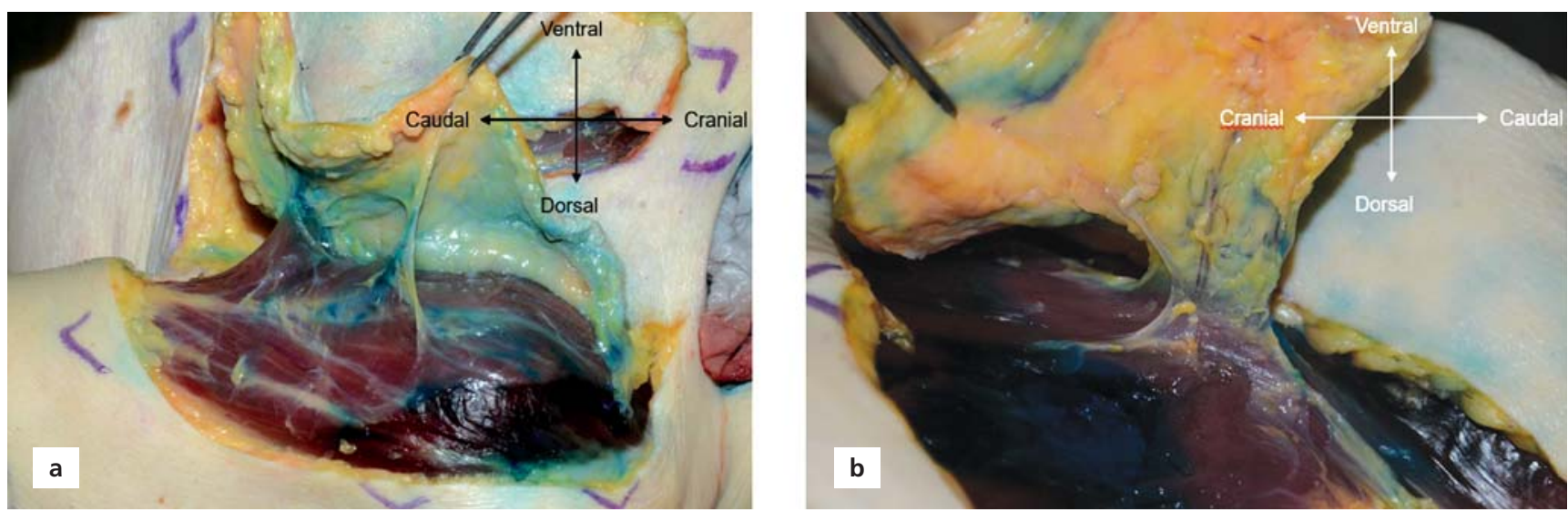

Figure 3. Identification and dissection of the vascular territory (a) and perforators (b) of the deltoid branch of the thoracoacromial artery.

were the first choices in terms of reconstruction of the head and neck. ${ }^{[1,1,14]}$ Unfortunately, functional and aesthetic requirements limit their use today. Indeed, research is increasingly directed towards the flaps corresponding exactly to the characteristics of the recipient

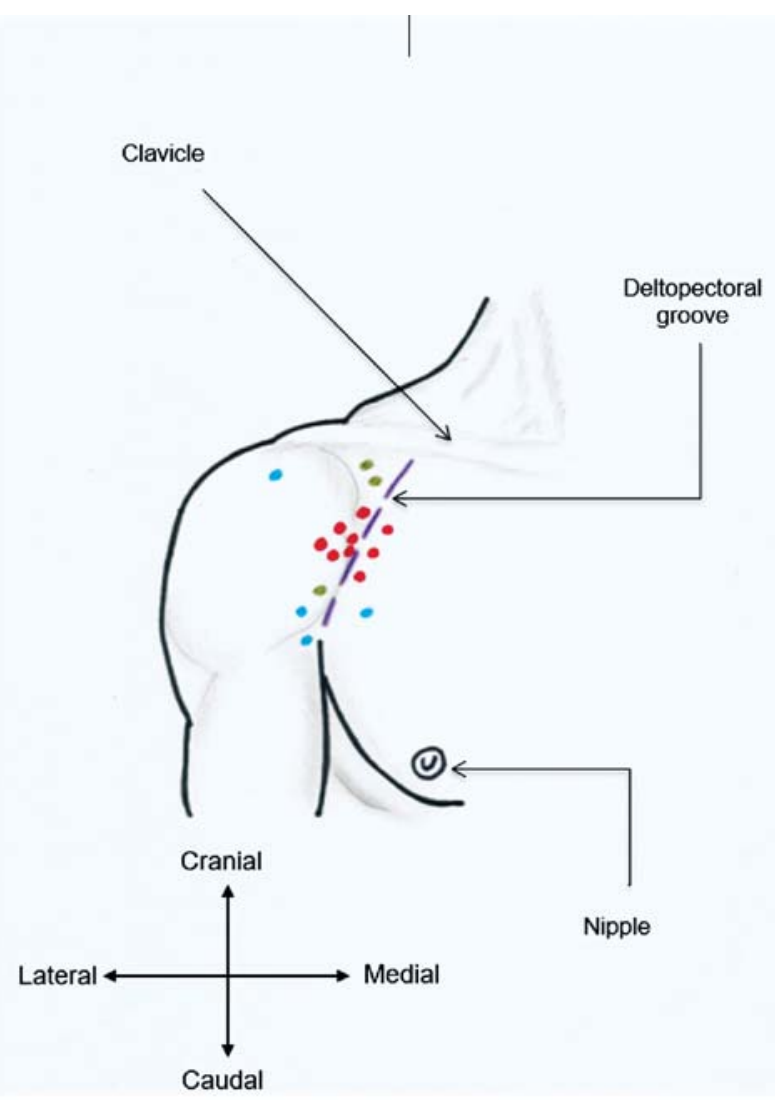

Figure 4. Distribution of the perforator of the deltoid branch of the thoracoacromial artery based on incidence. Blue: $<40 \%$; green: between 40 and $70 \%$; red: $>70 \%$. site, with a lower morbidity of the donor site. The main disadvantages of these two flaps concern a high rate of necrosis, the need for a skin graft to cover the donor site, and a low rotation angle due to the short length of the pedicle. ${ }^{[13,14]}$ We also believe that these two flaps are not

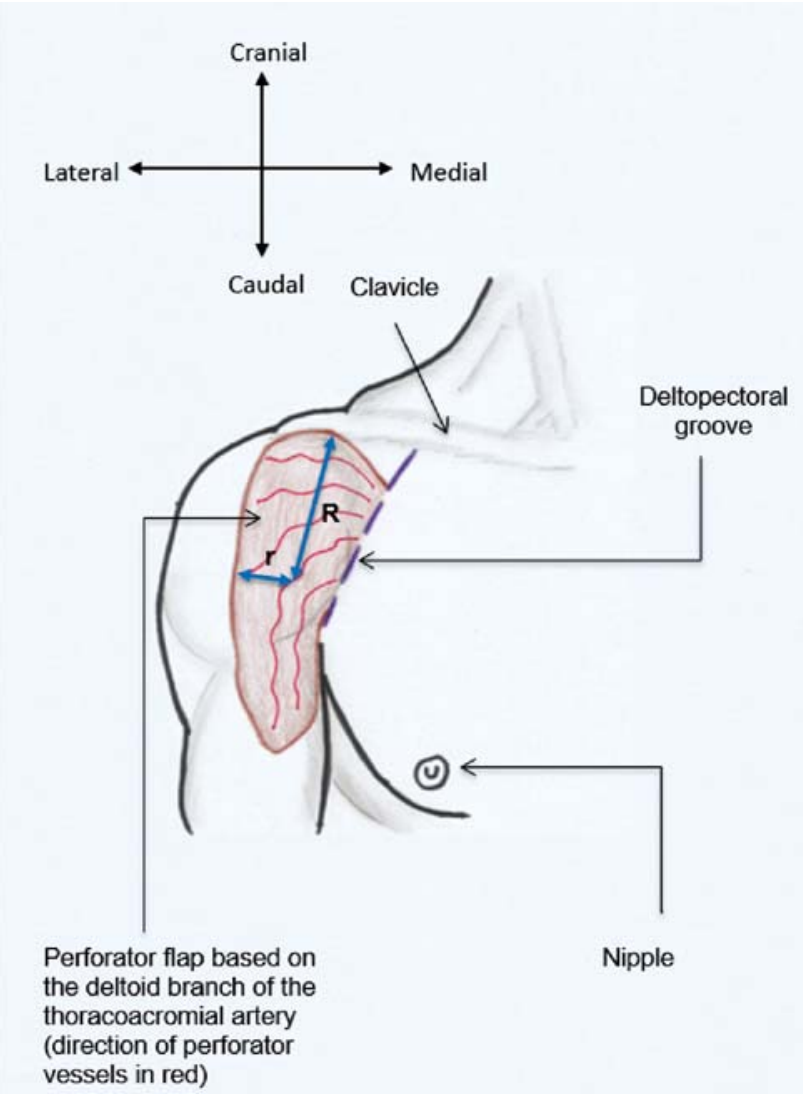

Figure 5. Drawing of the perforator flap (range, 6-7 cm) based on the deltoid branch of the thoracoacromial artery. R: long radius; $r$ : small radius. 

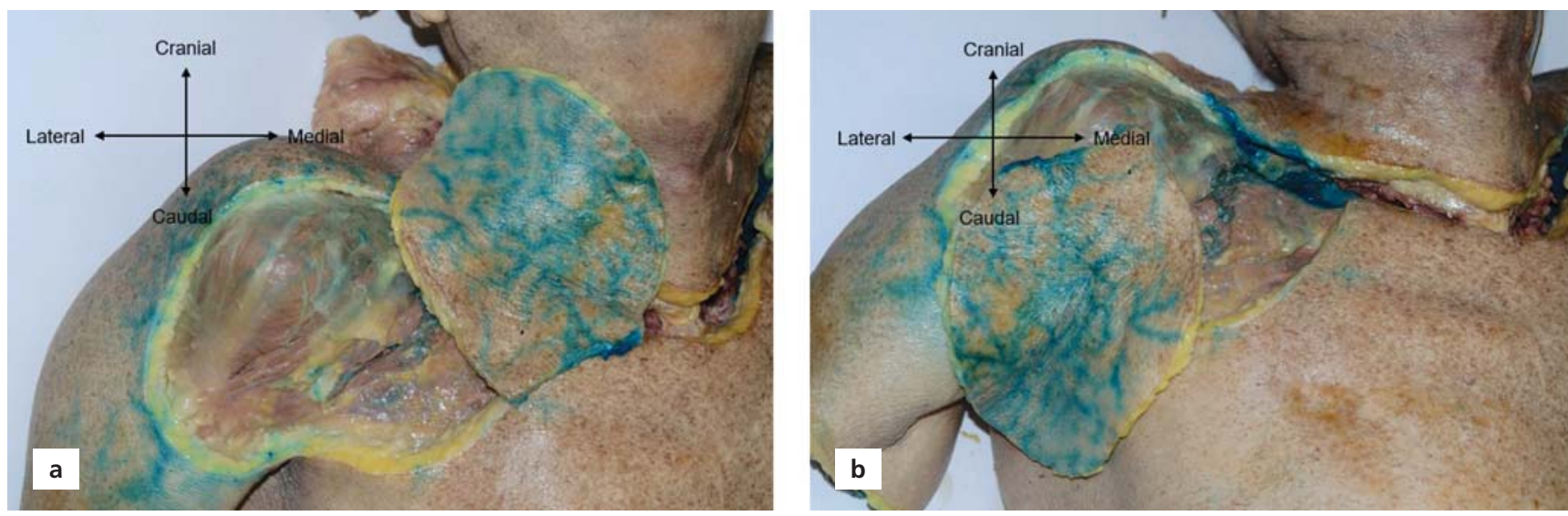

Figure 6. Skin flap pedicled on the perforators of the thoracoacromial artery can be used to reach axillary (a) and cervical (b) regions.

Table 1

Summary of the findings in the 24 dissected specimens.

\begin{tabular}{|c|c|c|c|c|c|c|c|c|c|c|c|c|}
\hline No & Age & Sex & $\begin{array}{c}\text { Diameter } \\
\text { of TAA } \\
\text { (mm) }\end{array}$ & $\begin{array}{l}\text { Number of } \\
\text { deltoid } \\
\text { perforators } \\
\text { found }\end{array}$ & $\begin{array}{l}\text { Min. } \\
\text { diameter } \\
\text { of deldoid } \\
\text { perforators } \\
(\mathrm{mm})\end{array}$ & $\begin{array}{c}\text { Max. } \\
\text { diameter } \\
\text { of deltoid } \\
\text { perforators } \\
\text { (mm) }\end{array}$ & $\begin{array}{c}\text { Average } \\
\text { diameter } \\
\text { of deltoid } \\
\text { perforators } \\
(\mathrm{mm})\end{array}$ & $\begin{array}{l}\text { Dimensions } \\
\text { of deltoid } \\
\text { branch's } \\
\text { perforasome } \\
\quad(\mathrm{cm})\end{array}$ & $\begin{array}{l}\text { Length of } \\
\text { extrafascial } \\
\text { pedicle } \\
(\mathrm{cm})\end{array}$ & $\begin{array}{l}\text { Length of } \\
\text { pedicle after } \\
\text { transmuscular } \\
\text { dissection } \\
\text { (cm) }\end{array}$ & $\begin{array}{c}\text { Arc of } \\
\text { rotation } \\
\text { from } \\
\text { pivot } \\
\text { point ( }\left(^{\circ}\right)\end{array}$ & Side \\
\hline 1 & 72 & $\mathrm{M}$ & 2 & 2 & 0.8 & 1.2 & 1 & $9 \times 5$ & 1.5 & 6 & 180 & L \\
\hline 2 & 72 & $\mathrm{M}$ & 2 & 3 & 0.5 & 1.5 & 1 & $7 \times 5$ & 1.5 & 9 & 180 & $R$ \\
\hline 3 & 58 & $\mathrm{M}$ & 2 & 3 & 1 & 1 & 1 & $7 \times 5$ & 1.5 & 10 & 180 & L \\
\hline 4 & 58 & $\mathrm{M}$ & 1.5 & 2 & 0.8 & 1.3 & 1 & $5 \times 9$ & 2 & 8 & 180 & $\mathrm{R}$ \\
\hline 5 & 63 & $\mathrm{M}$ & 2 & 2 & 1 & 1 & 1 & $7 \times 5$ & 1.5 & 5 & 180 & $\mathrm{~L}$ \\
\hline 6 & 63 & $M$ & 2.5 & 2 & 0.5 & 1 & 0.8 & $6 \times 7$ & 1.5 & 6 & 180 & $R$ \\
\hline 7 & 88 & $\mathrm{M}$ & 1 & 1 & 0.5 & 0.5 & 0.5 & $5 \times 7$ & 2 & 10 & 180 & L \\
\hline 8 & 88 & $\mathrm{M}$ & 1 & 3 & 0.6 & 1.5 & 1.1 & $5 \times 7$ & 1.5 & 8 & 180 & $\mathrm{R}$ \\
\hline 9 & 67 & $M$ & 2 & 2 & 0.8 & 1.2 & 1 & $6 \times 8$ & 1.5 & 5 & 180 & $\mathrm{~L}$ \\
\hline 10 & 67 & $\mathrm{M}$ & 2 & 3 & 0.7 & 1 & 0.9 & $6 \times 9$ & 2 & 7 & 180 & $R$ \\
\hline 11 & 64 & $M$ & 2 & 2 & 0.6 & 1 & 0.8 & $5 \times 9$ & 1.5 & 9 & 180 & $\mathrm{~L}$ \\
\hline 12 & 64 & $\mathrm{M}$ & 1.5 & 3 & 0.8 & 1 & 0.9 & $5 \times 7$ & 1 & 8 & 180 & $\mathrm{R}$ \\
\hline 13 & 75 & $\mathrm{M}$ & 1.5 & 2 & 1 & 1.2 & 1.1 & $6 \times 9$ & 2 & 6 & 180 & $\mathrm{~L}$ \\
\hline 14 & 75 & $\mathrm{M}$ & 1.5 & 3 & 0.8 & 1.2 & 1 & $5 \times 8$ & 1.5 & 6 & 180 & $\mathrm{R}$ \\
\hline 15 & 87 & $\mathrm{~F}$ & 2 & 3 & 0.8 & 1.2 & 1 & $6 \times 9$ & 2.5 & 5 & 180 & $\mathrm{~L}$ \\
\hline 16 & 87 & $\mathrm{~F}$ & 2 & 1 & 0.8 & 0.8 & 0.8 & $8 \times 5$ & 2.5 & 6 & 180 & $\mathrm{R}$ \\
\hline 17 & 82 & $\mathrm{M}$ & 2.5 & 2 & 0.5 & 0.9 & 0.7 & $6 \times 8$ & 2 & 7 & 180 & $\mathrm{~L}$ \\
\hline 18 & 82 & $\mathrm{M}$ & 2.5 & 2 & 0.9 & 1.3 & 1.1 & $6 \times 7$ & 1.5 & 8 & 180 & $\mathrm{R}$ \\
\hline 19 & 69 & $\mathrm{~F}$ & 2.5 & 3 & 0.8 & 1.2 & 1 & $6 \times 8$ & 2 & 9 & 180 & L \\
\hline 20 & 69 & $\mathrm{~F}$ & 2 & 3 & 0.5 & 1 & 0.7 & $5 \times 7$ & 1.5 & 8 & 180 & $R$ \\
\hline 21 & 57 & $\mathrm{M}$ & 3 & 2 & 0.8 & 1 & 0.9 & $6 \times 9$ & 3 & 5 & 180 & L \\
\hline 22 & 57 & $\mathrm{M}$ & 3 & 3 & 0.5 & 0.9 & 0.7 & $8 \times 7$ & 2.5 & 6 & 180 & $R$ \\
\hline 23 & 47 & $\mathrm{~F}$ & 1.5 & 3 & 0.8 & 1.2 & 1 & $6 \times 9$ & 1.5 & 6 & 180 & L \\
\hline 24 & 47 & $\mathrm{~F}$ & 2 & 3 & 0.6 & 1.5 & 1.1 & $5 \times 9$ & 1.5 & 5 & 180 & $R$ \\
\hline
\end{tabular}

TAA: thoracoacromial artery. 
suitable for the most superficial tissue defect in the cervical region, because of their excessive thickness.

The pedicled flaps on the musculocutaneous perforator arteries have several advantages compared to conventional musculocutaneous flaps, in particular during reconstructions in soft tissue defects of head and neck. ${ }^{[5,6]}$ The proximity of these flaps to the head and neck gives them an additional advantage in filling tissue defects of these regions (Figure 6). The absence of hair is also a positive point. In this region, the pedicled flap on the transverse cervical artery is the most used ${ }^{[4]}$ For many years, the perforator flap of the transverse cervical artery made easier filling in soft tissues defects of neck and face. Indeed, it fulfills several reconstruction criteria including proximity to the head, good technical flexibility during its harvesting, as well as similarities with head and neck in terms of hairiness, texture, coloring and thickness. ${ }^{[4]}$ Compared to the perforator flap of the transverse cervical artery, our work shows that the perforator flap of the deltoid branch of the TAA has excellent quality in addition to a long transmuscular pedicle (Figure 6). It spares the deltoid muscle in all cases, which decreases the morbidity of the donor site. The donor site can sometimes be primarily closed (according to the flap size and shape) or grafted. However, the perforator flap of the deltoid branch of the TAA has not yet been the subject of important anatomical studies to date.

According to Salmon, ${ }^{[10,1]}$ the TAA is the main integumentary artery in the anterior portion of the deltoid region. It is divided in depth into two branches: one acromial (the deltopectoral artery) and the other thoracic (or pectoral). Our results are similar to those reported by Thomas et al. ${ }^{[15]}$ According to their study, the upper limb presents on average 15 territories irrigated by 48 perforators. The average caliber of the perforators is $0.7 \mathrm{~mm}$ and the perforasomes cover an average surface of $35 \mathrm{~cm} 2$. Our work shows that the general orientation of the perforators in the adipose tissue is oblique laterocaudally, parallel to the deltopectoral groove, as stated by Salmon. ${ }^{[10]}$ However, for dissected specimens presenting 2 or 3 perforators, even if the small branches have different orientations, they are close to the oblique orientation described above. In our dissection experience, the perforator flap based on the deltoid branch of the TAA can be lifted craniocaudally on the proximal part of the upper limb and placed on a recipient site in a lateromedial position within the lateral triangle of the neck, or in a caudocranial position within the anterior cervical region (Figure 5). However, harvesting and placing the flap must respect its original orientation (craniocaudal or slightly oblique below and laterally according to
Salmon), the anatomical limits and the average flap dimensions.

The drawing of the flap is therefore possible while respecting the general orientation of the perforators of the deltoid branch of the TAA, the anatomical limits of the perforasome, and the point of origin of the terminal branches of the TAA at the deltopectoral groove. When we perform a retrograde dissection of the perforasome and then the perforator while respecting the middle third of the deltopectoral groove as a landmark, the pedicle obtained from the deltoid branch of the TAA to its axillary origin can measure up to $10 \mathrm{~cm}$ long. Despite the fact that the deltoid branch of the TAA gives a constant number of perforators which irrigate the subcutaneous tissue and skin of the supero-anterior region of the upper limb, none of these perforators is observed below the horizontal line passing through the nipple and extending over the arm. The perforasome irrigated by the deltoid branch of the TAA is limited by: the horizontal line passing through the nipple caudally, the vertical line passing through the insertion of the deltoid muscle laterally, the anterior margin of the deltoid muscle medially, and the apex of the flap lying near its pedicle, up to the middle third of the deltopectoral groove. When dissecting this flap, it is better to include the acromial branch of the TAA and the territory assigned to it. Because the acromial branch is always a daughter branch from the deltoid branch as proved by our study. In addition, when it is born early (a few millimeters after the birth of the deltoid branch) it projects like its original branch against the middle third of the deltopectoral groove. During dissections, our experience of harvesting and placing flaps shows that, even if the vascular territory of the deltoid branch covers in all cases the lateral triangle of the neck, in 19 dissections out of 24 the anterior region of the neck is easily accessible by this flap. In 5 cases the pedicle's length is insufficient. To reach cervical regions, a slow and careful transmuscular dissection of the pedicle should be performed.

The work of Hue et al. ${ }^{[16]}$ shows that the deltoid flap is taken from a vascular transition zone. In fact, the deltoid muscle flap receives three vascular pedicles dividing it into three regions. These pedicles are represented by the deltoid branch of the TAA and the posterior and anterior humeral circumflex arteries. In fact, it is common during the preparation of the deltoid muscle flap to injure the collaterals of the TAA. ${ }^{[16]}$ The arterial vascularization of the deltoid muscle is organized as follows: ${ }^{[3,16]}$ the posterior humeral circumflex artery provides the main vascular source, followed by the anterior 
humeral circumflex artery, then by the deltoid branch of the TAA. The posterior humeral circumflex artery has the largest caliber and constitutes the vascular base of the muscular and musculocutaneous flaps of the deltoid. ${ }^{[3,16]}$ However, in our work it appears that the deltoid branch represents an important vascular source for the anterior surface of the deltoid muscle.

For all our injections, the perforasome corresponding to the deltoid branch of the TAA occupies only a part of the skin corresponding to the deltoid muscle. For this reason, the surgeon must take precautions when harvesting this perforator flap.

We might think that the perforator flap based on the deltoid branch of the TAA represents the perforator variant of the deltoid muscle flap. Actually, the deltoid branch of the TAA is only the smallest arterial source of the deltoid muscle. ${ }^{[3]}$ Besides, the cutaneous perforasome corresponding to this deltoid branch covers only the anterior part of the deltoid subcutaneous tissue and skin. It would therefore be interesting to complete our work with another anatomical study focusing on cutaneous perforasomes from perforator branches of the posterior and anterior humeral circumflex arteries. Another limitation of our study lies in the fact that all the dissected subjects are of Caucasian type. It would be interesting to make our sample more consistent, by including other races in order to compare these first results.

Despite the popularity of the perforator flap of the transverse cervical artery in the correction of cervicofacial tissue defects, the perforator flap of the deltoid branch of the TAA can be used for the same indications. But that requires a careful pedicle dissection. In our experience, it could even be used for loss of pectoral or back tissues. In practice, the surgeon has to perform a preoperative localization of the perforators, using a CT scan or a Doppler ultrasound.

\section{Conclusion}

The deltoid branch of the TAA gives several perforators which supply the subcutaneous tissue and skin of the anterior part of the deltoid region. These branches can be used as a vascular base for harvesting perforator flaps within the deltoid muscle, in order to fill in tissue defect from the lateral triangle of the neck and the anterior cervical region.

\section{Acknowledgments}

The authors are grateful for the contribution of the entire staff of the Lille University Anatomy Laboratory (France) to this work, along with the staff of the Radiology
Department of the Lille University Hospital. The authors of this work thank all the donors for their contribution.

\section{Conflict of Interest}

All authors declare no conflict of interest.

\section{Author Contributions}

PMMN: protocol, project development, data collection, data analysis, and manuscript writing; CF: protocol development, data analysis, and manuscript editing; VD-M: protocol development, data analysis, and manuscript editing; XD: protocol development, data analysis, and manuscript editing.

\section{Ethics Approval}

All the institutional procedures concerning cadaveric dissection were respected, as well as the ethical framework.

\section{Funding}

No funding received.

\section{References}

1. Ross RJ, Baillieu CE, Shayan R, Leung M, Ashton MW. The anatomical basis for improving the reliability of the supraclavicular flap. J Plast Reconstr Aesthet Surg 2014;67:198-204.

2. Alves HR, Ishida LC, Ishida LH, Besteiro JM, Gemperli R, Faria JCM, Rereira MC. A clinical experience of the supraclavicular flap used to reconstruct head and neck defects in late-stage cancer patients. J Plast Reconstr Aesthet Surg 2012;65:1350-6.

3. Munnoch DA, Morris AM, Herbert KJ. The deltoid muscle flap: anatomical studies and case reports. Br J Plast Surg 1996;49:310_4.

4. Kneser U, Beier JP, Dragu A, Arkudas A, Horch RE. Transverse cervical artery perforator propeller flap for reconstruction of supraclavicular defects. J Plast Reconstr Aesthet Surg 2011;64:952-4.

5. Morris SF, Tang M, Almuktari K, Geddes C, Yang D. The anatomic basis of perforator flaps. Clin Plast Surg 2010;37:553-70.

6. Manyacka Ma Nyemb P, Fontaine C, Demondion X, Demeulaere $M$, Descamps F, Ndoye J-M. Anatomical variations of the trunk of origin and terminal branches of the thoraco-acromial artery. MOJ Anat Physiol 2018;5:57-61.

7. Geddes CR, Tang M, Yang D, Morris SF. An assessment of the anatomical basis of the thoracoacromial artery perforator flap. Can J Plast Surg 2003;11:23-7.

8. Hallock GG. The island thoracoacromial artery muscle perforator flap. Ann Plast Surg 2011;66:168-71.

9. Reid CD, Taylor GI. The vascular territory of the acromiothoracic axis. Br J Plast Surg 1984;37:194-212.

10. Salmon M, Grégoire R. Artères de la peau (Vol. 4). Paris (France): Masson; 1936. p. 123-31.

11. Salmon M, Dor J. Les artères des muscles des membres et du tronc. Paris (France): Masson; 1933. p. 238

12. Liu R, Gullane P, Brown D, Irish J. Pectoralis major myocutaneous pedicled flap in head and neck reconstruction: retrospective review of 
indications and results in 244 consecutive cases at the Toronto General Hospital. J Otolaryngol 2001;30:34-40.

13. Wei WI, Chan YW. Pectoralis major flap. In: Wei FC, Mardini S, editors. Flaps and reconstructive surgery. Philadelphia (PA): Saunders; 2009. p. 175-192.

14. Nishi Y, Rikimaru H, Kiyokawa K, Watanabe K, Koga N, Sakamoto A. Development of the pectoral perforator flap and the deltopectoral perforator flap pedicled with the pectoralis major muscle flap. Ann Plast Surg 2013;71:365-71.

ORCID ID:

P. Manyacka Ma Nyemb 0000-0002-3339-4312;

C. Fontaine 0000-0001-9280-7546;

V. Duquennoy-Martinot 0000-0003-4296-9736;

X. Demondion 0000-0003-2418-4396

deomed.

15. Thomas BP, Geddes CR, Tang M. The vascular supply of the integument of the upper extremity. In: Blondeel PN, Morris SF, Hallock GG, Neligan PC, editors. Perforator flaps: anatomy, technique and clinical applications. St Louis (MO): QMP; 2006. p. 129-246.

16. Hue E, Gagey O, Mestdagh H, Fontaine C, Drizenko A, Maynou C. The blood supply of the deltoid muscle. Application to the deltoid flap technique. Surg Radiol Anat 1998;20:161-5.

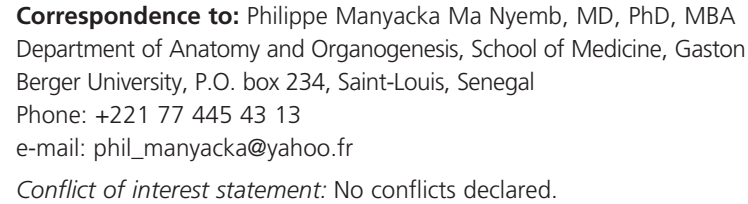

This is an open access article distributed under the terms of the Creative Commons Attribution-NonCommercial-NoDerivs 4.0 Unported (CC BY-NCND4.0) Licence (http://creativecommons.org/licenses/by-nc-nd/4.0/) which permits unrestricted noncommercial use, distribution, and reproduction in any medium, provided the original work is properly cited. How to cite this article: Manyacka Ma Nyemb P, Fontaine C, Duquennoy-Martinot V, Demondion X. Perforator flaps based on the deltoid branch of the thoracoacromial artery: anatomical study. Anatomy 2021;15(1):36-43. 